\title{
OPEN ${ }^{89} \mathrm{Zr}$ anti-CD44 immuno-PET monitors CD44 expression on splenic myeloid cells and HT29 colon cancer cells
}

Jin Won Park ${ }^{1,4}$, Kyung-Ho Jung ${ }^{2,3,4}$, Jin Hee Lee ${ }^{2,3}$, Seung Hwan Moon ${ }^{2}$, Young Seok Cho ${ }^{2}$ \& Kyung-Han Lee ${ }^{2,3 凶}$

CD44 is a cell-surface glycoprotein involved in cell-cell interaction, adhesion, and migration. CD44 is found on colon cancer cells and on immune cells. Previous studies of ${ }^{89} \mathrm{Zr} \mathrm{PET}$ imaging of CD44 have relied on an anti-human antibody (Ab), which can influence biodistribution in murine models. In this study, we used an Ab that cross-reacts with both human and mouse origin CD44 of all isoforms to unveil the type of leukocyte responsible for high splenic anti-CD44 uptake and investigate how its regulation can influence tumor immuno-PET. The $A b$ was site-specifically labeled with ${ }^{89} \mathrm{Zr}$-deferoxamine on cysteine residues. ${ }^{89} \mathrm{Zr}$-anti-CD44 demonstrated high-specific binding to HT29 human colon cancer cells and monocytic cells that showed CD44 expression. When ${ }^{89} \mathrm{Zr}$-anti-CD44 was administered to Balb/C nude mice, there was remarkably high splenic uptake but low SNU-C5 tumor uptake $(1.2 \pm 0.7 \% \mathrm{ID} / \mathrm{g})$. Among cells isolated from Balb/C mouse spleen, there was greater CD44 expression on CD11b positive myeloid cells than lymphocytes. In cultured monocytic and macrophage cells, LPS stimulation upregulated CD44 expression and increased ${ }^{89} \mathrm{Zr}$-anti-CD44 binding. Similarly, normal Balb/C mice that underwent lipopolysaccharide (LPS) stimulation showed a significant upregulation of CD44 expression on splenic myeloid cells. Furthermore, LPS treatment stimulated a 2.44-fold increase of ${ }^{89} \mathrm{Zr}$-anti-CD44 accumulation in the spleen, which was attributable to splenic myeloid cells. Finally, in Balb/C nude mice bearing HT29 tumors, we injected ${ }^{89} \mathrm{Zr}$-anti-CD44 with greater $A b$ doses to reduce binding to splenic cells. The results showed lower spleen uptake and improved tumor uptake $(2.9 \pm 1.3 \% \mathrm{ID} / \mathrm{g})$ with a total of $300 \mu \mathrm{g}$ of $\mathrm{Ab}$ dose, and further reduction of spleen uptake and greater tumor uptake $(5.7 \pm 0.0 \% \mathrm{ID} / \mathrm{g})$ with $700 \mu \mathrm{g} \mathrm{Ab}$ dose. Thus, using an ${ }^{89} \mathrm{Zr}$ labeled $A b$ that cross-reacts with both human and mouse CD44, we demonstrate that CD44 immunoPET has the capacity to monitor CD44 regulation on splenic myeloid cells and may also be useful for imaging colon tumors.

CD44 is a multifunctional, non-kinase, single-pass transmembrane glycoprotein involved in cell-cell and cellextracellular matrix interactions ${ }^{1}$. Malignant cells expressing CD44 are associated with tumor initiation and tumorsphere formation capacity that leads to cancer progression and poor patient outcome. Indeed, CD44 is a major marker of cancer stemness as characterized by self-renewal capacity, epithelial-mesenchymal transition, and treatment resistance ${ }^{1}$. CD44 thus provides an attractive target for cancer treatment ${ }^{2-4}$, and radiolabeled anti-CD44 antibodies (Abs) are being investigated for targeted imaging ${ }^{5-9}$, as well as radio-immunotherapy of solid tumors ${ }^{10,11}$.

However, CD44 is also expressed on leukocytes, where it plays roles in cell mobilization and function ${ }^{12}$. In the body, the spleen serves as the largest secondary lymphoid organ and hosts large numbers of phagocytic myeloid cells as well as lymphocytes ${ }^{13}$. Immune staining confirmed CD44 expression on leukocytes in the human spleen and facilitated its micro-anatomical compartmentalization ${ }^{14}$. Among many different splice variants of CD44, certain variants such as CD44v6 is reported to have a more restricted expression in a subset of epithelial tissues and mostly epithelial tumors. In contrast, Abs directed against the constant domain of CD44 is likely to target

\footnotetext{
${ }^{1}$ Scripps Korea Antibody Institute, 1, Kangwondeahak-gil, Chuncheon-si, Gangwon-do, Korea. ${ }^{2}$ Department of Nuclear Medicine, Samsung Medical Center, 50 Ilwon-dong, Gangnam-gu, Seoul, Korea. ${ }^{3}$ Department of Health Sciences and Technology, SAIHST, Sungkyunkwan University School of Medicine, Seoul, Korea. ${ }^{4}$ These authors contributed equally: Jin Won Park and Kyung-Ho Jung. ${ }^{\varpi}$ email: khleenm@naver.com
} 
other tissues such as splenic leukocytes in addition to tumor cells. Immuno-PET using such Abs could thus yield useful information regarding splenic immune responses ${ }^{17,18}$.

Among splenic leukocytes, myeloid cells that include monocytes/macrophages and neutrophils have discrete immune functions with central roles in cellular stress, foreign material removal, and immune response regulation ${ }^{15}$. Myeloid cells become activated and upregulated in function by inflammatory stimuli, and lipopolysaccharide (LPS) stands out as a major stimulator through the classical activation pathway ${ }^{16}$. LPS released from bacteria enters the circulation to stimulate the immunologic system by activating myeloid cells. Indeed, activation response to LPS is one of the best characterized pathogen-associated molecular patterns that cause phagocytic cells to switch to an inflammatory phenotype without leaving the tissue.

A previous study using an ${ }^{89} \mathrm{Zr}$-labelled anti-human CD44 Ab observed high uptake in human cancer xenografts with low spleen uptake in mice but found remarkably high splenic uptake in non-human primates ${ }^{7}$. Therefore, in vivo biodistribution and imaging findings in human cancer-bearing mice that better predicts the results in human subjects will be benefited from the use of an Ab that cross-reacts with both murine and human CD44.

This aim of this study was to use an Ab that reacts with all CD44 isoforms of both human and mouse origin to unveil how splenic leukocyte activation affects spleen uptake of ${ }^{89} \mathrm{Zr}$-anti-CD44 and to dissect the leukocyte type responsible for this effect. We further investigated how regulating the magnitude of splenic leukocyte uptake by total $\mathrm{Ab}$ dose can influence tumor accumulation.

\section{Results}

Deferoxamine (DFO) conjugation and site-specific ${ }^{89} \mathrm{Zr}$ labeling of anti-CD44 Ab. IM7 Ab was site-specifically conjugated with ${ }^{89} \mathrm{Zr}$ on cysteine residues in a straightforward manner. The Ab was first reduced through reaction with tris(2-carboxyethyl)phosphine (TCEP) and then underwent conjugation with deferoxamine (DFO)-maleimide. Non-reduced SDS-PAGE analysis demonstrated complete reduction of target disulfide bonds of the Ab by TCEP, which remained reduced after DFO-conjugation (Fig. $1 \mathrm{~A}) .{ }^{89} \mathrm{Zr}$ radiolabeling of deferoxamine-conjugated anti-CD44 was reproducible, with a labeling efficiency of $80 \%$. Radiochemical purity was $>99 \%$, and the specific activity was $59.2 \mathrm{MBq} / \mathrm{mg}$. Autoradiography of column-eluted ${ }^{89} \mathrm{Zr}$-anti-CD44 showed a clear radioactive band at the expected $170 \mathrm{kD}$ region (Fig. 1A). Radiochemical stability by radioinstant thin layer chromatography (radio-iTLC) analysis showed that the radiolabel was more than $95 \%$ intact after up to $96 \mathrm{~h}$ incubation in 50\% FBS or PBS (Fig. 1A).

CD44 expression on cancer cells and monocytic cells and specific ${ }^{89} \mathrm{Zr}$-anti-CD44 binding. Western blots confirmed clear protein bands of CD44 expression on human HT29 and SNU-C5 human colon cancer cells and THP-1 human monocytic cells (Fig. 1B). Cell binding experiments demonstrated that ${ }^{89} \mathrm{Zr}$-anti-CD44 binding to HT29 cells was almost completely blocked to $6.8 \pm 2.6 \%$ of controls by excess cold anti-CD44, confirming CD44-specific binding (Fig. 1B). Binding to THP-1 cells was also substantially blocked by excess cold anti-CD44 to $25.9 \pm 4.0 \%$ of controls (Fig. 1B).

${ }^{89} \mathrm{Zr}$-anti-CD44 biodistribution in normal mice and CD44 expression on splenic leukocytes. When ${ }^{89} \mathrm{Zr}$-anti-CD44 was intravenously injected into normal Balb/c mice, blood pharmacokinetic analysis using a two-phase decay model showed a slow K value of 0.07 and slow circulating half-life of $9.6 \mathrm{~h}$ (Fig-2A). Biodistribution data of ${ }^{89} \mathrm{Zr}$-anti-CD44 in SNU-C5 tumor-bearing Balb/c nude mice at 3- and 6-days post-injection are shown in Fig. 2A and Supplementary Table 1. The results revealed remarkably high uptake in the spleen that reached $64.8 \pm 8.0$ injected dose per gram tissue $(\% \mathrm{ID} / \mathrm{g})$ at day 6 (Fig. $2 \mathrm{~A})$. This was followed by modest uptake in the liver $(6.4 \pm 1.0 \% \mathrm{ID} / \mathrm{g})$. There was low uptake in the kidney, myocardium, lung, stomach, and muscle. Blood activity was quite low $(0.12 \pm 0.0 \% \mathrm{ID} / \mathrm{g})$. Tumor uptake in these animals was disappointingly low at $1.2 \pm 0.7 \% \mathrm{ID} / \mathrm{g}$ (Fig. $2 \mathrm{~A}$ ).

To investigate the cells responsible for the high ${ }^{89} \mathrm{Zr}$-anti-CD44 uptake, leukocytes were isolated from the spleen of normal mice. Flow cytometry with forward and side scatter plots displayed regions R1 and R2 that correspond to lymphocytes and myeloid cells, respectively (Fig. 2B). Dot plots using FITC-anti-CD44 and APC$\mathrm{CD} 11 \mathrm{~b}$ revealed that $\mathrm{R} 2$ cells were $\mathrm{CD} 11 \mathrm{~b}+/ \mathrm{CD} 44+$, indicating myeloid cells (Fig. 2B).

Effects of LPS stimulation on cultured macrophages and monocytic cells. When we tested the effect of LPS on cultured macrophage/monocytic cells, RAW264.7 macrophages showed that LPS significantly stimulated CD44 expression and increased ${ }^{89} \mathrm{Zr}$-anti-CD44 binding to $136.6 \pm 4.6 \%$ of that of controls (Fig. 3A). Similarly, THP-1 monocytic cells showed that LPS stimulation dose-dependently elevated CD44 expression and ${ }^{89} \mathrm{Zr}$-anti-CD44 binding. The latter reached $238.9 \pm 19.9 \%$ of untreated controls by $1 \mu \mathrm{M}$ LPS (Fig. 3B).

Effect of LPS treatment of mice on CD44 expression of splenic leukocytes. Flow cytometry histograms of R1 and R2 region splenic leukocytes using FITC-anti-CD44 showed that, although there was a greater number of CD44-positive cells in region R1, the level of CD44 expression was substantially higher for cells in region R2 (Fig. 4). This implied greater contribution of myeloid cells to high splenic ${ }^{89} \mathrm{Zr}$-anti-CD44 uptake.

When we treated normal mice with daily intraperitoneal injection with LPS for 3 days, CD44-positive splenic leukocytes in region R2 increased substantially from $9.3 \%$ to $24.8 \%$. In contrast, cells in region R1 showed a decrease of CD 44 -positivity from $78.3 \%$ to $58.3 \%$ (Fig. 4). This indicates that LPS simulates CD44 expression in splenic myeloid cells. 
A
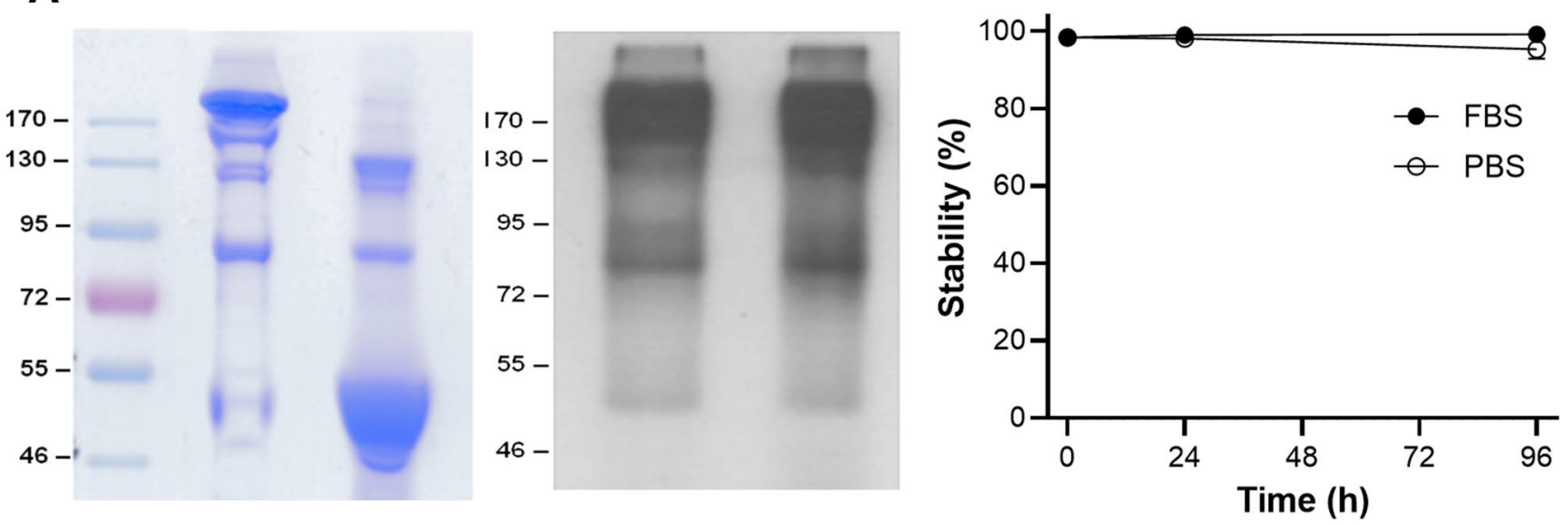

B

HT29 human colon cancer cells

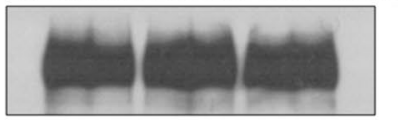

$-95 k D$

SNU-C5 human colon cancer cells

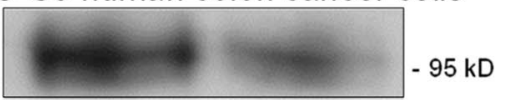

THP-1 human monocytic cells
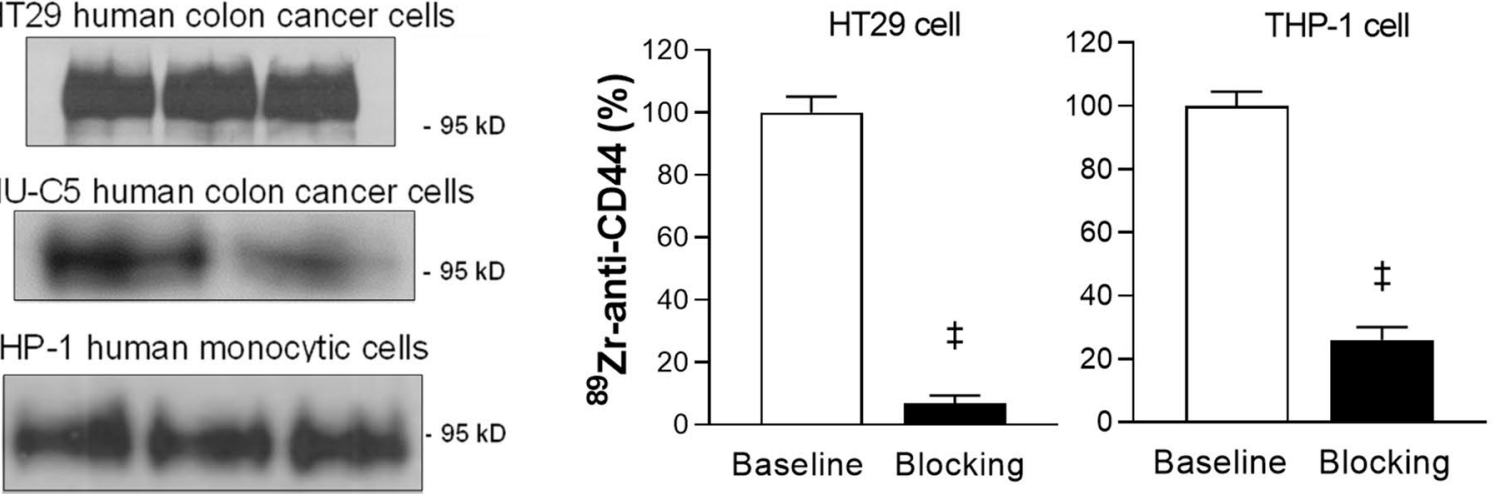

Figure 1. ${ }^{89} \mathrm{Zr}$-anti-CD44 preparation, stability, and CD44-specific binding. (A) Non-reduced SDS polyacrylamide gel electrophoresis (PAGE) of unmodified and deferoxamine-conjugated anti-CD44 (left). Autoradiograph of ${ }^{89} \mathrm{Zr}$-anti-CD44 on native PAGE (middle), and in vitro stability in PBS and FBS $(\mathrm{n}=4)$ assessed by radio-instant thin layer chromatography (right). (B) CD44 expression on HT29 human colon cancer cells and THP-1 human monocytic cells (left). Blots were cropped to combine into a single figure (see supplementary Fig. S1 for the full-length blots). CD44-specific cell binding of ${ }^{89} \mathrm{Zr}$-anti-CD44 that was blocked by excess $(500 \mathrm{nM})$ cold anti-CD44 (right). Bars are mean \pm S.D. of $\%$ bound activity from triplicate samples per group. $\ddagger P>0.001$.

Effects of LPS on ${ }^{89}$ Zr-anti-CD44 PET and biodistribution in normal mice. On in vivo LPS treatment experiments, PET/CT imaging of wild type Balb/c mice at baseline demonstrated high splenic uptake of ${ }^{89} \mathrm{Zr}$-anti-CD44, and this was substantially increased by following LPS treatment (Fig. 5A).

Biodistribution data confirmed remarkably high splenic uptake at baseline that was even greater than that observed in Balb/c nude mice (127.8 $\pm 13.5 \% \mathrm{ID} / \mathrm{g}$; Fig. 5B; Supplementary Table 1$)$. This was thought to reflect differences in the characteristics of splenic leukocytes between the two mouse strains ${ }^{19}$. In addition, since the nude mice had tumors that were substantially larger than the spleen, this took up a significant portion of the administered $\mathrm{Ab}$ dose, leaving somewhat less to be taken up by the spleen. In normal mice, splenic uptake was further increased 2.44-fold after LPS treatment $(P<0.001$; Fig. 5B). Uptake in the liver was slightly increased by LPS treatment, whereas uptake in other organs were not affected.

When ${ }^{89} \mathrm{Zr}$-anti-CD44 uptake in splenic cells isolated from normal mice were compared, unsorted splenic leukocytes showed uptake increased to $160.7 \pm 5.0 \%$ of that of controls by LPS stimulation $(P=0.003$; Fig. 5C). R2 region myeloid cells sorted by flow cytometry showed a greater increase of uptake by LPS stimulation to $333.17 \pm 29.1 \%$ of that of controls $(P=0.008)$, whereas there was no change in uptake for R1 region lymphocytes (Fig. 5C).

Effects of Ab dose on ${ }^{89} \mathrm{Zr}$-anti-CD44 PET imaging and HT29 tumor uptake. Finally, we investigated ${ }^{89} \mathrm{Zr}$-anti-CD44 biodistribution in mice administered with elevated $\mathrm{Ab}$ doses. This was based on the notion that elevated $\mathrm{Ab}$ doses might reduce splenic cell binding of the radiotracer, thus allowing greater delivery to and accumulation by the tumor. When ${ }^{89} \mathrm{Zr}$-anti-CD44 was injected into HT29 tumor-bearing Balb/c nude mice with a total Ab dose of $300 \mu \mathrm{g}, \mathrm{PET} / \mathrm{CT}$ images at day 4 demonstrated clearly visible HT29 tumors and showed splenic uptake that appeared lower than previous observed with low Ab dose (Fig. 6A). When ${ }^{89} \mathrm{Zr}$-anti-CD44 

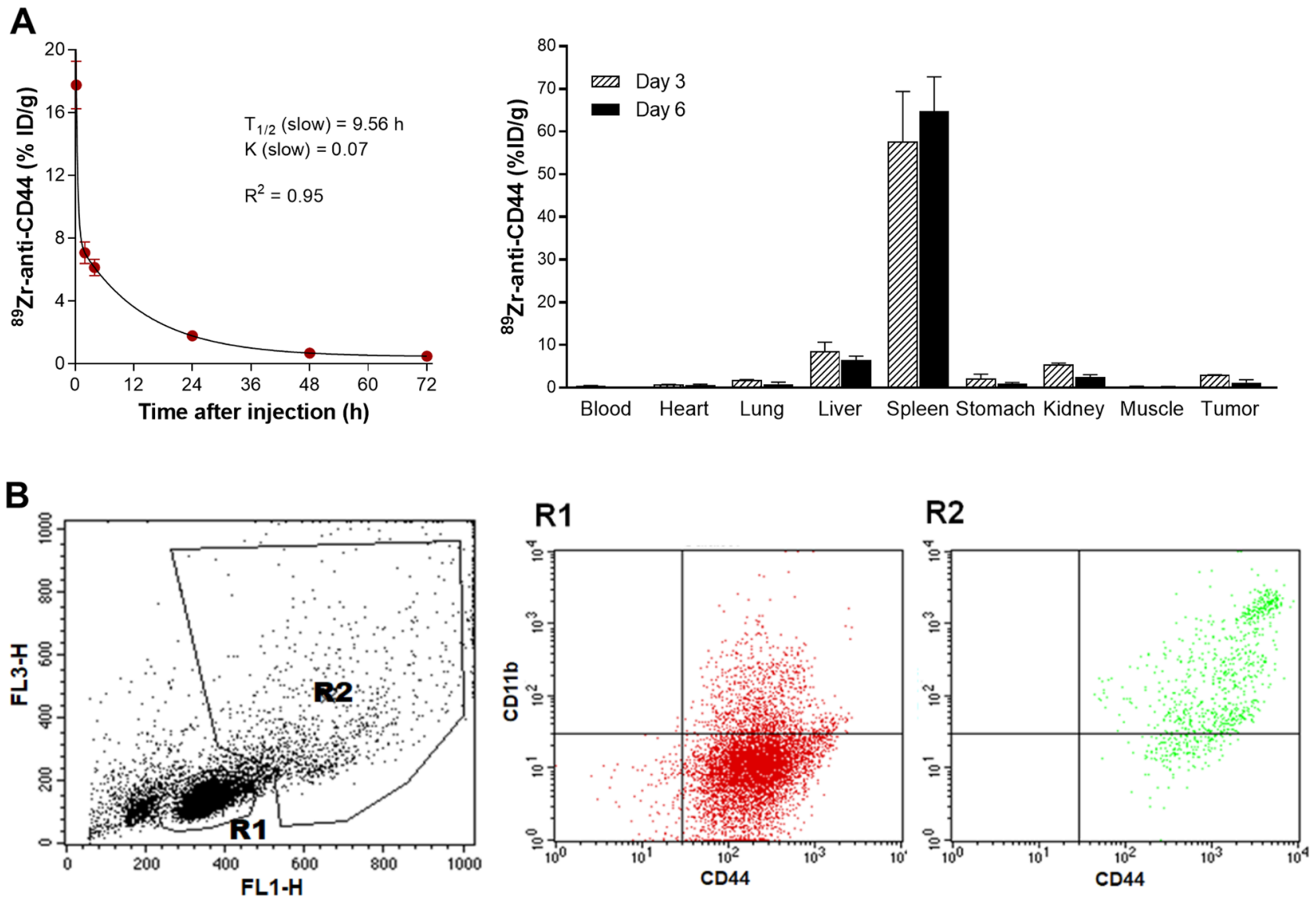

Figure 2. ${ }^{89} \mathrm{Zr}$-anti-CD44 pharmacokinetics and biodistribution in mice, and CD44 expression on leukocytes from mouse spleen. (A) ${ }^{89} \mathrm{Zr}$-anti-CD44 pharmacokinetics in normal Balb/c mice $(\mathrm{n}=5)$ and biodistribution in SNU-C5 tumor-bearing Balb/c nude mice $(n=4)$ after intravenous injection. Data are mean \pm S.D. of \% ID/g. (B) CD44 and CD11b expression on leukocytes isolated from the spleen of a normal Balb/c mouse. Singlecell suspensions were obtained by mincing the spleen. Representative flow cytometry forward and side scatter analysis plots (left) demonstrate the R1 region that corresponds to lymphocytes and R2 region that corresponds to myeloid cells. Flow cytometry with FITC-anti-CD44 and APC-anti-CD11b (right) reveal that cells of the R2 region are $\mathrm{CD} 11 \mathrm{~b}+/ \mathrm{CD} 44+$.

was injected with a total $\mathrm{Ab}$ dose of $700 \mu \mathrm{g}$, PET images showed further reduced spleen uptake and further increase of HT29 tumor uptake (Fig. 6A).

Biodistribution data confirmed the PET findings (Fig. 6B and Supplementary Table 1). Thus, ${ }^{89} \mathrm{Zr}$-anti-CD44 uptake in the spleen was $25.2 \pm 3.4 \% \mathrm{ID} / \mathrm{g}$ with an $\mathrm{Ab}$ dose of $300 \mu \mathrm{g}$, and further reduced to $13.8 \pm 1.4 \% \mathrm{ID} / \mathrm{g}$ with an Ab dose of $700 \mu \mathrm{g}(P<0.001$; Fig. 6B). HT29 tumor uptake that was $2.9 \pm 1.3 \% \mathrm{ID} / \mathrm{g}$ with an Ab dose of $300 \mu \mathrm{g}$ was increased two-fold with an $\mathrm{Ab}$ dose of $700 \mu \mathrm{g}$ to $5.7 \pm 0.0 \% \mathrm{ID} / \mathrm{g}(P<0.01$; Fig. $6 \mathrm{~B})$. Blood level showed a trend for slight increase by $700 \mu \mathrm{g} \mathrm{Ab}$ dose, while uptake in at other major organs was not influenced.

\section{Discussion}

In this study, we developed an immuno-PET technique that can noninvasively image CD44 status in target tissues of living bodies. The monoclonal rat IgG2b isotype Ab used in this study called IM7 is widely used for CD44 research ${ }^{20-22}$. Labeling of IM7 with ${ }^{89} \mathrm{Zr}$ (3.3-days physical half-life) allowed delayed imaging required for $\mathrm{Ab}$ probes with long circulating times. The DFO-maleimide conjugation technique that we used leads to cysteinespecific conjugation as a way of tailoring the location of ${ }^{89} \mathrm{Zr}$ attachment for PET imaging ${ }^{23,24}$. SDS PAGE analysis indicted that TCEP treatment led to site-specific reduction and deferoxamine conjugation of IM7. This offers advantages for immuno-PET through greater radioprobe homogeneity and immuno-reactivity compared to nonspecific radiolabeling approaches. ${ }^{89} \mathrm{Zr}$-anti-CD44 showed target-specific binding to CD44-positive HT29 colon cancer cells that was almost completely blocked by excess cold $\mathrm{Ab}$, indicating high immuno-reactivity.

IM7 recognizes an epitope common to alloantigens and all isoforms of CD44 ${ }^{25}$. Among many different splice variants of CD44, certain variants such as CD44v6 is reported to have a more restricted expression in a subset of epithelial tissues and mostly epithelial tumors. In contrast, Abs directed against the constant domain of CD44 is likely to target other tissues in addition to tumor cells.

In our biodistribution studies in mice, there was low blood concentration and high tissue-to-blood contrast on three- and six-days post-injection. Notably, ${ }^{89} \mathrm{Zr}$-anti-CD44 showed remarkably high probe accumulation in the spleen. ${ }^{89} \mathrm{Zr}$-based PET imaging of CD44 was first explored in a study that used an anti-human Ab called RG7356, 
A
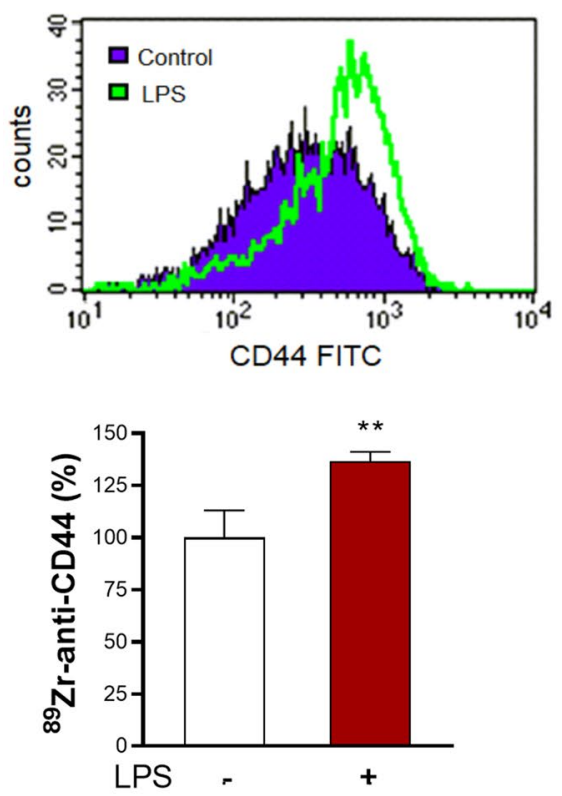

B
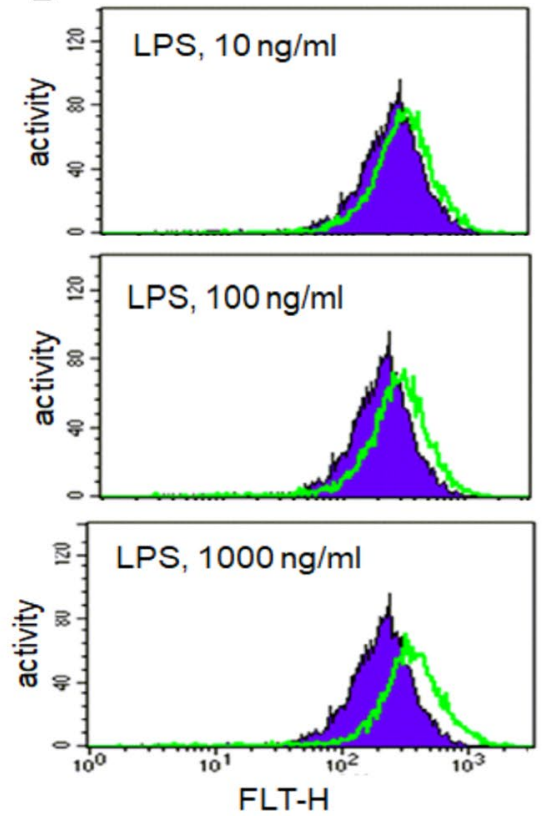

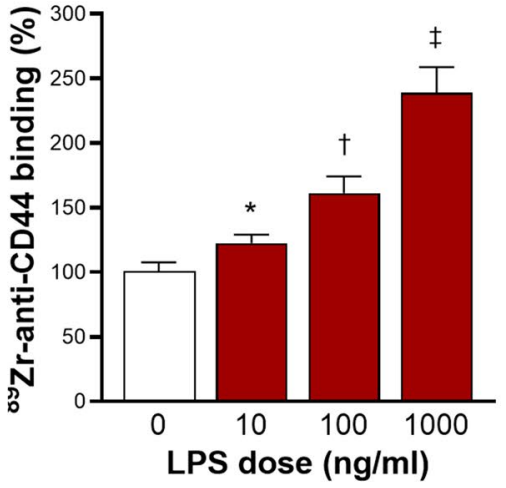

Figure 3. LPS stimulates CD44 expression and ${ }^{89} \mathrm{Zr}$-anti-CD44 uptake in cultured monocytic cells. (A,B) RAW264.7 murine macrophages (A) and THP-1 human monocytic cells (B) show increased CD44 expression and ${ }^{89} \mathrm{Zr}$-anti-CD44 uptake after LPS stimulation. Purple regions and green lines indicate control and LPSstimulated cells, respectively. Bars are mean \pm S.D. of $\%$ activity obtained from triplicate samples. ${ }^{*} P>0.05$; ${ }^{* *} P>0.01 ;{ }^{\dagger} P>0.005 ;{ }^{\ddagger} P>0.001$, compared to untreated controls.
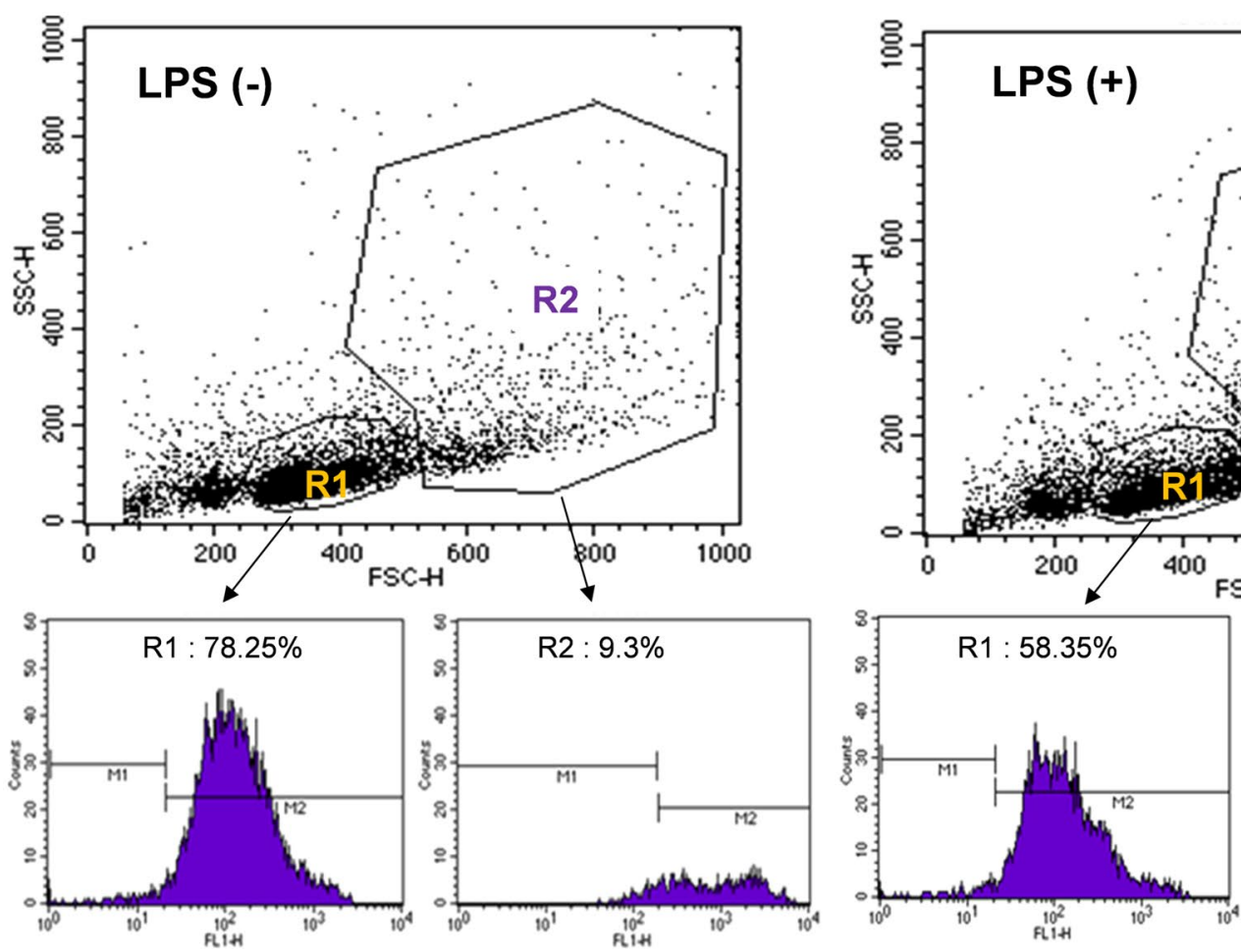

Figure 4. CD44 expression on leukocytes isolated from spleen of mice with or without LPS treatment.

Representative forward and side scatter analysis plots show an increase of cells in R2 after mice were treated with LPS (top). Flow cytometry histograms using FITC-anti-CD44 show that LPS stimulates a substantial increase of CD44 expression on cells in R2 but not R1 (bottom). 
A
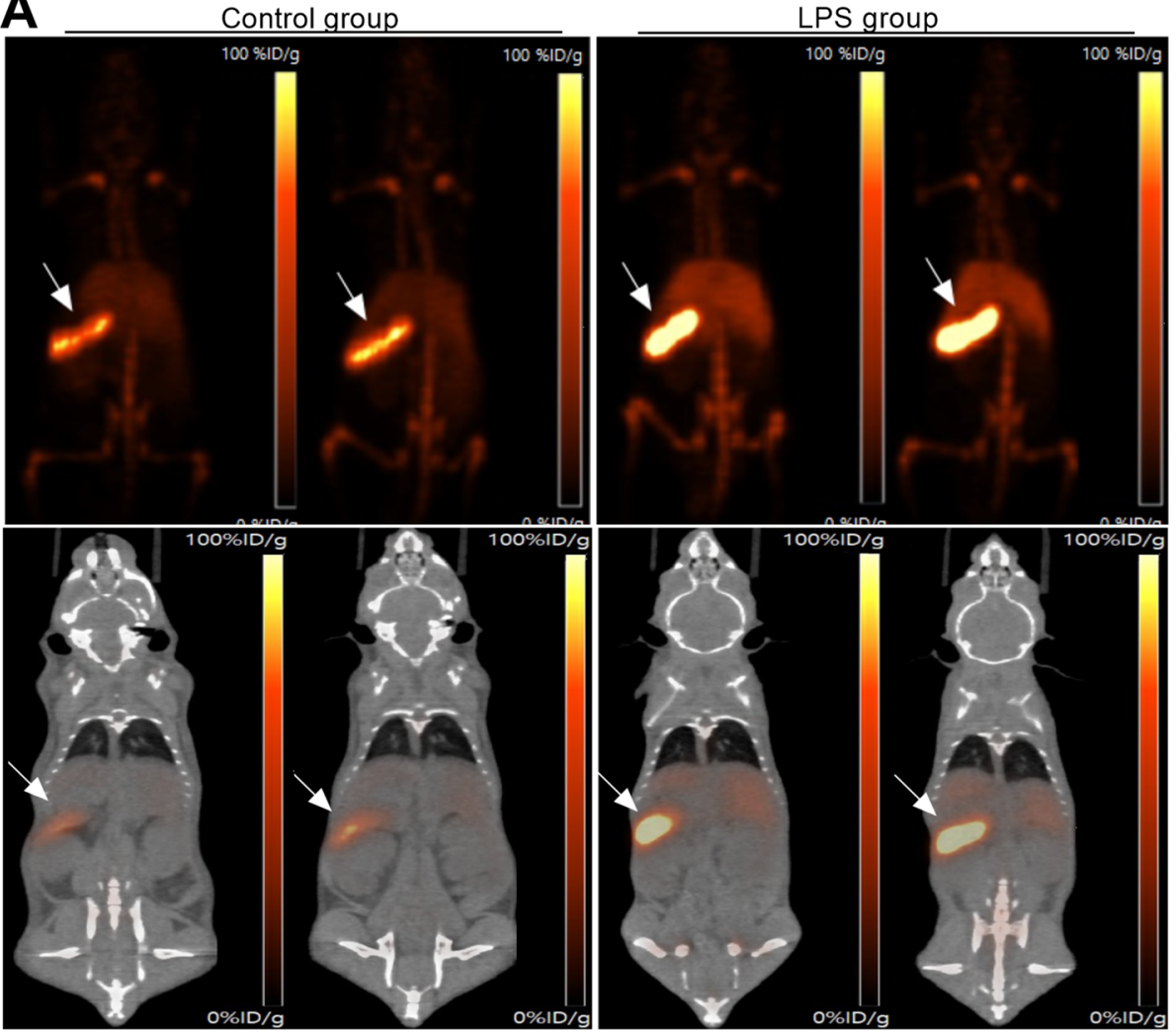

B

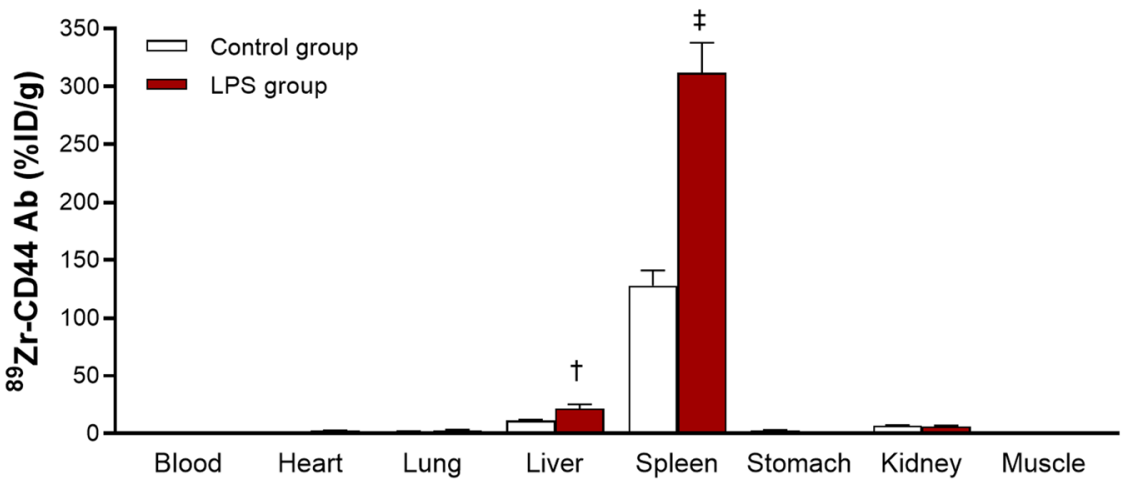

\section{C}
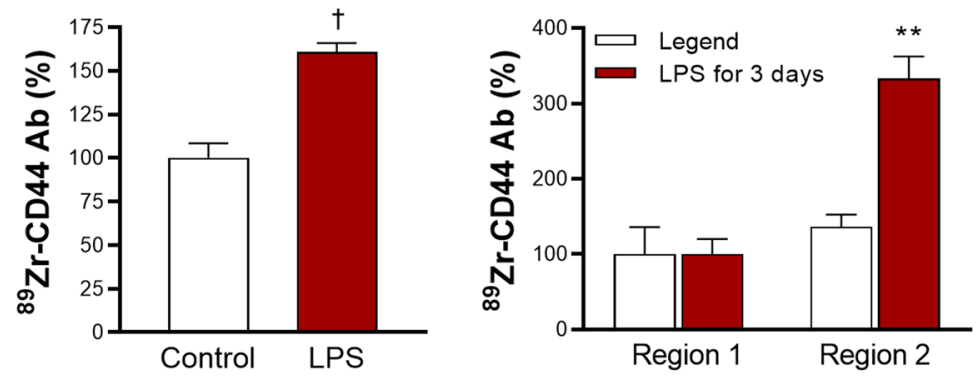

Figure 5. PET/CT imaging, biodistribution, and splenic cell binding of ${ }^{89} \mathrm{Zr}$-anti-CD44. (A) Representative maximum intensity projection (MIP) images (top) and coronal (bottom) PET/CT images of two wild type mice per group after daily injection for 3 days with saline (control) or $50 \mu \mathrm{g} / \mathrm{kg}$ LPS. ${ }^{89} \mathrm{Zr}$-anti-CD44 was injected on the second day, and imaging was performed 4 days later. Arrows indicate splenic uptake. (B) Biodistribution in saline- and LPS-treated mice immediately after PET/CT. (C) Effects of LPS on ${ }^{89} \mathrm{Zr}$-anti-CD44 uptake in leukocytes obtained from spleens of normal naive mice. On the left are unsorted splenic leukocytes, and on the right are cells from R1 and R2. Bars are mean \pm S.D. of \%ID/g obtained from 4 animals per group (B) or \% activity obtained from triplicate samples $(\mathbf{C}) .{ }^{* *} P>0.01 ;{ }^{\dagger} P>0.005 ;{ }^{\ddagger} P>0.001$, compared to controls. 
A
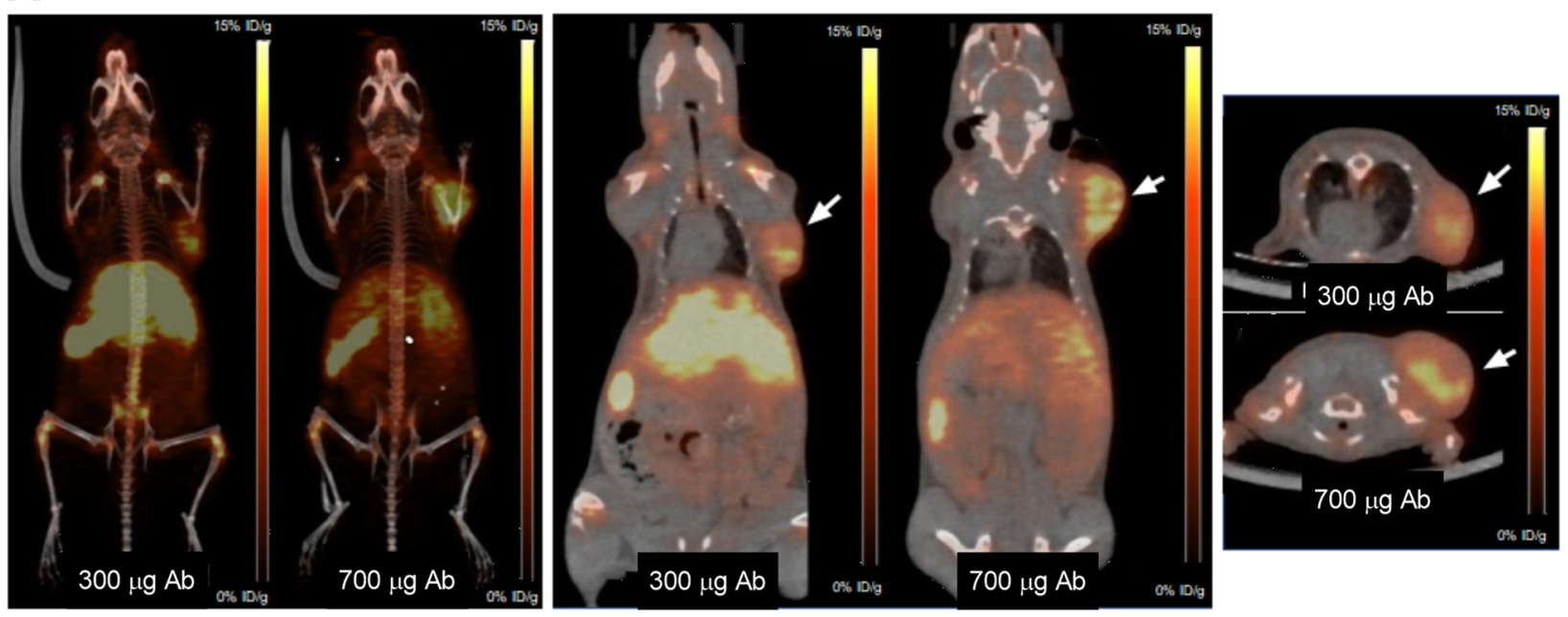

B

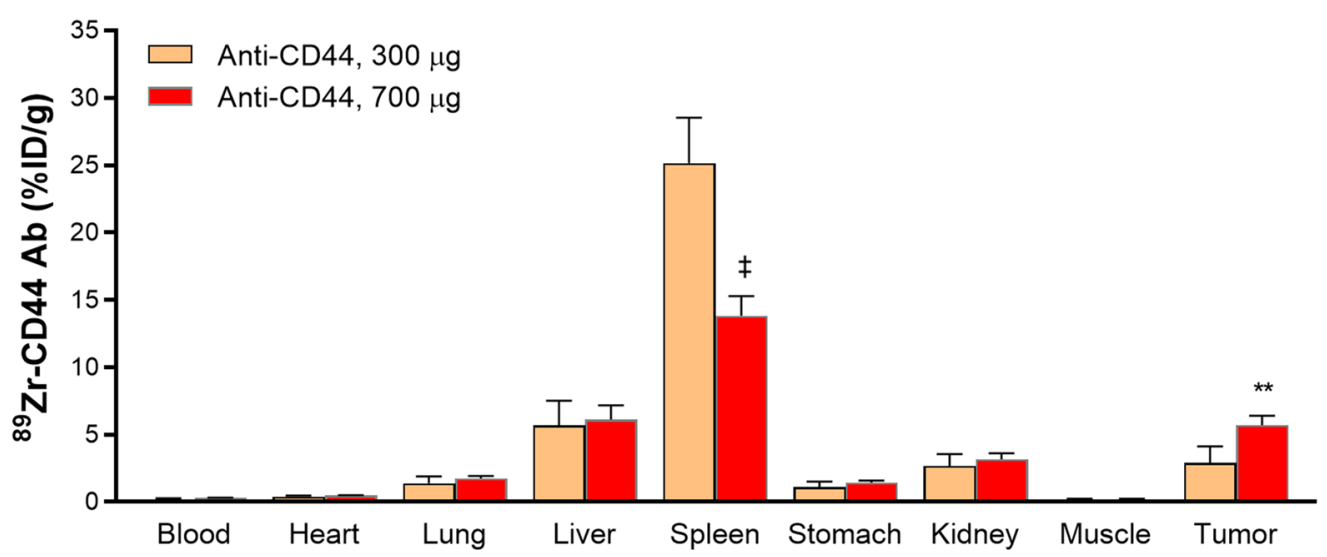

Figure 6. $\mathrm{PET} / \mathrm{CT}$ imaging and biodistribution of ${ }^{89} \mathrm{Zr}$-anti-CD44 in tumor bearing mice. (A) Representative MIP (left), coronal (middle), and transaxial (right) PET/CT images of HT29 tumor- bearing Balb/c nude mice at 4 days after injection of ${ }^{89} \mathrm{Zr}$-anti-CD44 with 300 or $700 \mathrm{ng}$ total $\mathrm{Ab}$ doses. Arrows indicate tumor uptake. (B) Biodistribution at 4 days after injection of ${ }^{89} \mathrm{Zr}$-anti-CD44 with 300 or $700 \mathrm{ng}$ total Ab doses. Bars are mean \pm S.D. of $\% \mathrm{ID} / \mathrm{g}$ obtained from four animals per group. ${ }^{* *} P>0.01 ;{ }^{\ddagger} P>0.001$.

and demonstrated high uptake in human breast cancer xenografts of mice ${ }^{7}$. However, because RG7356 does not cross-react with murine CD44, it does not provide information regarding CD44 expression in physiologically normal organs of the host. ${ }^{89} \mathrm{Zr}$-labeled RG7356 was therefore further injected into monkeys as a cross-reactive species and revealed remarkably high uptake in the spleen ${ }^{7}$. A first-in-human trial of ${ }^{89} \mathrm{Zr}$-labeled RG7356 in patients with solid malignancies also demonstrated high splenic uptake that required co-injection of excess cold $\mathrm{Ab}$ to achieve tumor targeting ${ }^{8,9}$. These previous studies indicate that radiolabeled Abs raised against the constant domain of CD44 protein of the host species accumulate to high levels in the spleen. This includes antibodies against murine CD44 in mice and antibodies against human CD44 in monkey models or human subjects.

Because IM7 reacts with both human and mouse CD44, we expected ${ }^{89} \mathrm{Zr}$-anti-CD44 to target both human CD44-expressing tumors and host splenic tissue. However, even though SNU-C5 human colon cancer cells expressed CD44 protein, ${ }^{89} \mathrm{Zr}$-anti-CD44 uptake in SNU-C5 tumors was disappointingly low. The remarkably high uptake in the spleen indicates that the spleen acted as a sink organ, which took up the bulk of the administered ${ }^{89} \mathrm{Zr}$-anti-CD44 before it had a chance to accumulate in the tumor tissue. CD44 is expressed on leukocytes abundant in the spleen. Among splenic leukocytes, certain lymphocytes express CD44, and studies have shown that $\mathrm{T}$ lymphocyte effector function is activated by CD $44^{26,27}$. The spleen also contains a large number of monocytes/macrophages and lower numbers of neutrophils that express high levels of CD44.

Given the high level of ${ }^{89} \mathrm{Zr}$-anti-CD44 uptake in the spleen, we dissected which types of cells were chiefly responsible for this finding. Leukocyte size and granule content can be assessed by forward and side scatter measurements on flow cytometry, respectively. Hence, lymphocytes are identified as small cells containing small granules, while monocyte/macrophages are identified as larger cells with granules ${ }^{28-31}$. On flow cytometry, splenic lymphocytes were separated into region $\mathrm{R} 1$ and splenic myeloid cells including monocyte/macrophages and neutrophils into region $\mathrm{R} 2$. That region $\mathrm{R} 2$ contained myeloid cells was confirmed by positive CD11b expression, an 
integrin receptor present on monocytes, macrophages, and neutrophils ${ }^{32}$. Functionally, CD11b regulates adhesion and migration of these cells ${ }^{32-34}$. Myeloid cells of region R2 also revealed high CD44 expression that was significantly greater than that exhibited by lymphocytes of region R1. Together, these finding indicate that myeloid cells are responsible for the high ${ }^{89} \mathrm{Zr}$-anti-CD44 accumulation by the spleen. In the murine spleen, there are up to fivefold greater numbers of monocyte/macrophages than neutrophils ${ }^{35,36}$. Therefore, monocyte/macrophages likely contributed to splenic ${ }^{89} \mathrm{Zr}$-anti-CD44 uptake to a significantly greater extent than that of neutrophils.

We next tested how CD44 expression and ${ }^{89} \mathrm{Zr}$-anti-CD44 uptake in splenic leukocytes were influenced by immune activation. Regulation of CD44 expression plays a critical role in modulating phagocyte adhesion, migration, and inflammation. LPS is a bacterial cell wall component that modulates inflammatory responses. In phagocytic cells, LPS has been shown to increase CD44 expression and activate downstream inflammatory responses $^{37}$. In our study, when mice were treated with LPS, R2 splenic myeloid cells showed a substantial increase of CD44 expression, whereas R1 lymphocytes did not. We further tested the effects of LPS stimulation on cultured monocytic THP-1 and RAW264.7 cells and confirmed significant increase of CD44 expression. This is consistent with a previous study that observed LPS to increase CD44 expression in normal monocytes and THP- 1 cells $^{38}$. In our study, the increase of CD44 expression was accompanied by significant increase of ${ }^{89} \mathrm{Zr}$-anti-CD44 uptake. Furthermore, mice treated with LPS displayed significantly increased ${ }^{89} \mathrm{Zr}$-anti-CD44 uptake on PET images and biodistribution studies. Moreover, LPS treatment significantly increased ${ }^{89} \mathrm{Zr}$-anti-CD44 uptake in splenic myeloid cells of R2 but not splenic lymphocytes of R1. Taken together, our findings indicate that increased spleen uptake of ${ }^{89} \mathrm{Zr}$-anti-CD44 following LPS treatment represents upregulated CD44 expression on activated myeloid cells and largely on activated monocyte/macrophages.

Our results of splenic cell CD44 imaging has several clinical implications for immuno-PET using Abs raised against the constant domain of CD44 protein. For example, a better understanding of factors that influence anti-CD44 accumulation in non-tumor organs could help develop ways to increase CD44-targeted delivery to tumors ${ }^{2-4}$. In addition, the ability to image myeloid cell CD44 expression might assist in developing ways to intercept the splenic reservoir before their deployment to other sites ${ }^{18}$. Furthermore, imaging of myeloid cells may facilitate newer strategies to target the spleen for manipulating tolerance induction, tumor-induced myelopoiesis, and immune suppression therapies.

Finally, we attempted to improve tumor imaging with ${ }^{89} \mathrm{Zr}$-anti-CD44 by increasing the total dose of $\mathrm{Ab}$ injected. The reasoning behind this was that $\mathrm{Ab}$ dose can strongly affect biodistribution. Hence, elevated amounts of circulating $\mathrm{Ab}$ could partly saturate binding sites on splenic myeloid cells, thereby allow more ${ }^{89} \mathrm{Zr}$-anti-CD44 to reach the tumor for accumulation. The results revealed that administering ${ }^{89} \mathrm{Zr}$-anti-CD44 with a total $\mathrm{Ab}$ dose of $300 \mu \mathrm{g}$ indeed reduced the level of splenic uptake and improved tumor uptake compared to when $100 \mu \mathrm{g}$ was administered. Administering ${ }^{89} \mathrm{Zr}$-anti-CD44 with a total Ab dose of $700 \mu \mathrm{g}$ further reduced splenic uptake half-fold and augmented tumor uptake two-fold. These results provide a potential method to improve tumor imaging with ${ }^{89} \mathrm{Zr}$-anti-CD44 PET.

In conclusion, using an ${ }^{89} \mathrm{Zr}$ labeled $\mathrm{Ab}$ that cross-reacts with both human and mouse CD44, we show that CD44 immuno-PET has the capacity to monitor CD44 regulation on splenic myeloid cells and may also be useful for noninvasively imaging of tumors in mice by increasing Ab dose.

\section{Materials and methods}

Cell culture and reagents. THP-1 human monocytic cells and RAW264.7 murine macrophage cells were from the American Type Cell Culture. HT29 and SNU-C5 human colon cancer cells were from the Korea Cell Line Bank. Cells were maintained in $5 \% \mathrm{CO}_{2}$ at $37^{\circ} \mathrm{C}$ in RPMI-1640 media (Lonza, Basel, Swiss) supplemented with $10 \%$ fetal bovine serum (FBS; Serena, Germany), $2 \mathrm{mM} \mathrm{L}$-glutamine, and $100 \mathrm{U} / \mathrm{mL}$ penicillin-streptomycin (Lonza, Basel, Swiss). Lipopolysaccharide (LPS) from Sigma Chemicals (St. Louis, MO) was dissolved in dimethyl sulfoxide (DMSO) and applied to cells by addition to culture medium.

IM7, a rat monoclonal $\mathrm{Ab}$ against human and mouse CD44 that reacts with all CD44 isoforms, was from Bio-X Cell (Lebanon, NH). Rabbit antibodies against CD44 were from Abcam (UK, Cambridge), and horseradish peroxidase-conjugated secondary anti-rabbit antibodies were from Cell Signaling Technology (Danvers, MA).

Deferoxamine conjugation and site-specific ${ }^{89} \mathrm{Zr}$ labeling of anti-CD44 Ab. IM7 was site-specifically conjugated with DFO-maleimide on sulfohydryl residues as previously described ${ }^{23,24}$. Briefly, 2 mg of antiCD44 in a volume of $200 \mu \mathrm{l}(10 \mathrm{mg} / \mathrm{ml})$ was mixed with $100 \mathrm{mM}$ TCEP (Sigma Chemicals) at a molar ratio of $1: 100$ and incubated for $20 \mathrm{~min}$ at room temperature. Reduced anti-CD44 was diluted in $0.1 \mathrm{M}$ sodium phosphate containing $150 \mathrm{mM} \mathrm{NaCl}$ and $1 \mathrm{mM}$ ethylene diamine tetraacetic acid (EDTA). The Ab was then conjugated on the sulfohydryl residues with $56.4 \mu \mathrm{L}$ of $2 \mathrm{mM}(0.44 \mu \mathrm{M}) \mathrm{N}-(3,11,14,22,25,33$-hexaoxo-4,10,15,21,26,32-hexaaza-10,21,32-trihydroxytetratriacontane) maleimide (DFO-maleimide; Macrocyclics, TX) for 60 min at room temperature (RT). Ab-conjugated DFO was purified from unreacted DFO-maleimide by PD-10 column elution. ${ }^{89} \mathrm{Zr}$-oxalate (Korea Atomic Energy Research Institute) was neutralized with $2 \mathrm{M} \mathrm{Na}_{2} \mathrm{CO}_{3}$ and $74 \mathrm{MBq}$ of ${ }^{89} \mathrm{Zr}$ in $200 \mu \mathrm{l}$ was mixed with DFO-conjugated anti-CD44 in 0.5 M HEPES buffer ( $\mathrm{pH} 7.0$ ). After 60 min of incubation with tapping every $15 \mathrm{~min}$, the reaction mixture was eluted through a PD-10 column with $0.25 \mathrm{M}$ sodium acetate containing $0.5 \%$ gentisic acid to purify ${ }^{89} \mathrm{Zr}$-anti-CD44 from free ${ }^{89} \mathrm{Zr}$ and unconjugated DFO-maleimide. Collected fractions of $0.5 \mathrm{~mL}$ were counted on a high-energy $\gamma$-counter, and the peak activity fraction was used.

SDS-polyacrylamide gel electrophoresis (PAGE) and autoradiography. For non-reducing SDSPAGE, $2 \mu \mathrm{g}$ of intact, TCEP-reduced, and DFO-conjugated anti-CD44 was diluted with water and $5 \times$ nonreducing sample buffer without dithiothreitol (DTT). Samples were boiled at $95{ }^{\circ} \mathrm{C}$ for $10 \mathrm{~min}$ and then sepa- 
rated on an $8 \%$ sodium dodecyl sulfate (SDS) polyacrylamide gel by electrophoresis. The gel was subsequently stained with $0.5 \%$ Coomassie blue.

Autoradiography was also performed for ${ }^{89} \mathrm{Zr}$-anti-CD44 and was separated by $8 \%$ native PAGE with sample buffer free of SDS or DTT.

Radiochemical stability assessment. ${ }^{89} \mathrm{Zr}$-anti-CD44 was tested for radiochemical purity and stability by radio-iTLC as previously described ${ }^{23,24}$. ${ }^{89} \mathrm{Zr}$-anti-CD44 $(15 \mu \mathrm{lof} 1 \mathrm{mg} / \mathrm{ml} ; 555 \mathrm{kBq})$ was incubated with the same volume of FBS or PBS at $37^{\circ} \mathrm{C}$. At 0 , 1, or 4 days, $6 \mu$ of the samples were placed on an iTLC-SG glass microfiber chromatography paper impregnated with silica gel (Agilent Technologies, CA). Radio-TLC was performed using an eluent of $50 \mathrm{mM}$ EDTA (pH 5.5). In this condition, ${ }^{89} \mathrm{Zr}$-anti-CD44 remains at baseline, while free ${ }^{89} \mathrm{Zr}^{4+}$ ions and $\left[{ }^{89} \mathrm{Zr}\right.$ ]-EDTA migrate at the solvent front. We did not investigate migration of ${ }^{89} \mathrm{Zr}-\mathrm{DFO}$ in this study.

${ }^{89} \mathrm{Zr}$-CD44 cell binding assays. Cultured SNU-C5, HT29, RAW264.7, and THP-1 cells or cells obtained from mouse spleen were counted and $0.25 \times 10^{6}$ cells in $500 \mu \mathrm{l}$ of culture media were placed into $1.5 \mathrm{~mL}$ tubes. Cells were incubated for $1 \mathrm{~h}$ with $185 \mathrm{kBq}(0.36 \mu \mathrm{g})$ of ${ }^{89} \mathrm{Zr}$-anti-CD44 added to the media in $5 \% \mathrm{CO}_{2}$ at $37^{\circ} \mathrm{C}$. After rapid washing twice with $500 \mu \mathrm{l}$ of cold phosphate buffered saline (PBS), cells were measured for bound radioactivity on a high energy $\gamma$-counter (Perkin-Elmer). Excess cold $\mathrm{Ab}(500 \mathrm{nM})$ was used for blocking experiments. Uptake level of each sample was normalized for protein content.

Western blotting for CD44 protein. Western blots were performed as previously described ${ }^{24}$. Briefly, cells were washed with PBS and solubilized in PRO-PREP protein extraction solution (iNtRON Biotechnology, Korea) for $15 \mathrm{~min}$ at $4{ }^{\circ} \mathrm{C}$. Cell debris was eliminated by centrifugation at $14,000 \mathrm{rpm}$ for $10 \mathrm{~min}$ at $4{ }^{\circ} \mathrm{C}$. The supernatant was analyzed with Bradford protein assays, and $40 \mu \mathrm{g}$ of protein was separated on a $10 \%$ polyacrylamide gel. The protein bands were transferred to a PVDF membrane (Amersham Biosciences; Piscataway, $\mathrm{NJ})$ and incubated overnight at $4{ }^{\circ} \mathrm{C}$ with polyclonal antibodies against CD44 (1:1000) in Tris-buffered saline (50 mM Tris, $\mathrm{pH} 7.5,150 \mathrm{mM} \mathrm{NaCl}$ ) containing $0.05 \%$ Tween-20 and 5\% skim milk. After washing 3 times for $10 \mathrm{~min}$ each with tris-buffered saline with Tween-20, the membrane was incubated with secondary antibodies at RT for $1 \mathrm{~h}$. Immune reactive protein was finally detected with an enhanced chemiluminescence kit (Thermo Fisher Scientific, MA).

Preparation of single-cell suspensions from mouse spleen. All animal experiments were performed in accordance with the National Institutes of Health Guide for Care and Use of Laboratory Animals and approved by the Institutional Animal Care and Use Committee of Samsung Medical Center. This study was carried out in compliance with the ARRIVE guidelines (http://www.nc3rs.org.uk/page.asp?id=1357). Single-cell suspensions of mouse spleen were prepared following a Stem Cell Technologies Protocol (https://www.stemcell.com/howto-prepare-a-single-cell-suspension-from-mouse-spleen.html). Briefly, spleens extracted from normal 6-weekold male Balb/C mice sacrificed by cervical dislocation were minced in PBS by pressing with a syringe bar. The minced tissue solution was passed through a $100 \mu \mathrm{m}$ mesh strainer (Corning, NY) using $2 \times$ volume of PBS containing 2\% FBS. Cell debris was removed by 3 min centrifugation at $1200 \mathrm{rpm}$. Red blood cells in the pellet were removed by 5 min treatment with $\mathrm{RBC}$ lysis buffer $\left(10 \mathrm{mM}\right.$ Tris- $\mathrm{HCl}[\mathrm{pH} 7.3]$ containing $140 \mathrm{mM} \mathrm{NH}_{4} \mathrm{Cl}$ and $1 \mathrm{mM}$ EDTA), followed by rapid neutralization with PBS containing $2 \%$ FBS. The resultant single-cell suspension was finally washed twice with PBS containing 2\% FBS and used for flow cytometry.

Flow cytometry for CD11b and CD44 expression. RAW264.7 cells, THP-1 cells, or murine spleen cells $\left(1 \times 10^{6}\right.$ cells) were incubated for $30 \mathrm{~min}$ at $37^{\circ} \mathrm{C}$ with FITC-tagged anti-CD44 (BioLegend, CA, 1:200; $2.5 \mu \mathrm{g} / \mathrm{ml}$ ) or APC-tagged anti-CD44 (BD Biosciences; 1:200; $2.5 \mu \mathrm{g} / \mathrm{ml}$ ). The cells underwent FACS caliber flow cytometry analysis or FACS aria cell sorting (BD Biosciences). FITC fluorescence was detected with a $488 \mathrm{~nm}$ laser as excitation channel and $530 \mathrm{~nm}$ wavelength fluorescence as emission detector channel. APC fluorescence was detected by a combination of green 532-nm laser as excitation and 585/42-nm as the wavelength detector channel.

${ }^{89}$ Zr-anti-CD44 PET imaging and biodistribution. Pharmacokinetic studies, and LPS stimulation experiments with PET/CT imaging and biodistribution were performed in six-week-old male wild type Balb/C mice. Tumor-bearing models were prepared in six-week-old male Balb/C nude mice by subcutaneous injection of $5 \times 10^{6}$ HT29 cancer cells or SNU-C5 into the right flank. Biodistribution and PET/CT imaging studies were performed in the mice when tumor diameter reached approximately $1.0 \mathrm{~cm}$. All animals were injected into the tail vein with $3.7 \mathrm{MBq}$ of ${ }^{89} \mathrm{Zr}$-anti-CD44 that contained an $\mathrm{Ab}$ dose of $100 \mu \mathrm{g}$, unless additional cold anti-CD44 was added to increase total $\mathrm{Ab}$ dose. Imaging was performed under isoflurane anesthesia using a small-animal PET/CT scanner (Inveon; Siemens) without respiratory gating. Acquisition of non-enhanced CT images was followed by emission PET imaging. Animals were sacrificed immediately after imaging, and tissues were weighed and measured for radioactivity on a high-energy $\gamma$-counter (Parkin Elmer). Uptake levels were expressed as percentage of injected dose per gram of tissue $(\% \mathrm{ID} / \mathrm{g})$.

LPS stimulation was performed by daily intra-peritoneal injection of $50 \mu \mathrm{g}$ LPS in saline for 3 days (saline was injected for controls). ${ }^{89} \mathrm{Zr}$-anti-CD44 was injected on the second day of LPS treatment, and PET imaging was performed 4 days later. 
Statistical analysis. Data are mean \pm SD unless otherwise specified. Significant differences between two groups were analyzed by two-tailed unpaired Student's t-test. For three or more groups, ANOVA with Tukey's post-hoc test was used for comparison. $P$ values $<0.05$ were considered statistically significant.

Received: 7 August 2020; Accepted: 2 February 2021

Published online: 16 February 2021

\section{References}

1. Zöller, M. CD44: can a cancer-initiating cell profit from an abundantly expressed molecule?. Nat. Rev. Cancer 11, 254-267 (2011).

2. Ghosh, S. C., Neslihan Alpay, S. \& Klostergaard, J. CD44: a validated target for improved delivery of cancer therapeutics. Expert Opin. Ther. Targets 16, 635-650 (2012).

3. Tijink, B. M. et al. A phase I dose escalation study with anti-CD44v6 bivatuzumab mertansine in patients with incurable squamous cell carcinoma of the head and neck or esophagus. Clin. Cancer Res. 12, 6064-6072 (2006).

4. Jin, L., Hope, K. J., Zhai, Q., Smadja-Joffe, F. \& Dick, J. E. Targeting of CD44 eradicates human acute myeloid leukemic stem cells. Nat. Med. 12, 1167-1174 (2006).

5. Fortin, M. et al. Immuno-PET of undifferentiated thyroid carcinoma with radioiodine-labelled antibody cMAb U36: application to antibody tumour uptake studies. Eur. J. Nucl. Med. Mol. Imaging 34, 1376-1387 (2007).

6. Spiegelberg, D. et al. Molecular imaging of EGFR and CD44v6 for prediction and response monitoring of HSP90 inhibition in an in vivo squamous cell carcinoma model. Eur. J. Nucl. Med. Mol. Imaging 43, 974-982 (2016).

7. Vugts, D. J. et al. Preclinical evaluation of 89Zr-labeled anti-CD44 monoclonal antibody RG7356 in mice and cynomolgus monkeys: prelude to phase 1 clinical studies. MAbs 6, 567-575 (2014).

8. Menke-van der Houven, C. W. et al. First-in-human phase I clinical trial of RG7356, an anti-CD44 humanized antibody, in patients with advanced, CD44-expressing solid tumors. Oncotarget 7, 80046-80058 (2016).

9. Jauw, Y. W. S. et al. Assessment of target-mediated uptake with immuno-PET: analysis of a phase I clinical trial with an anti-CD44 antibody. EJNMMI Res. https://doi.org/10.1186/s13550-018-0358-8 (2018).

10. Mortensen, A. C., Spiegelberg, D., Haylock, A. K., Lundqvist, H. \& Nestor, M. Preclinical evaluation of a novel engineered recombinant human anti-CD44v6 antibody for potential use in radio-immunotherapy. Int. J. Oncol. 52, 1875-1885 (2018).

11. Börjesson, P. K. et al. Phase I therapy study with ${ }^{186}$ Re-labeled humanized monoclonal antibody BIWA 4 (bivatuzumab) in patients with head and neck squamous cell carcinoma. Clin. Cancer Res. 9, 3961S-S3972 (2003).

12. Johnson, P. \& Ruffell, B. CD44 and its role in inflammation and inflammatory diseases. Inflamm. Allergy Drug Targets 8, 208-220 (2009).

13. Bronte, V. \& Pittet, M. J. The spleen in local and systemic regulation of immunity. Immunity 39, 806-818 (2013).

14. Korkusuz, P., Dağdeviren, A. \& Aşan, E. Immunophenotypic analysis of human spleen compartments. Ann. Anat. 184, 431-441 (2002).

15. Gordon, S. The macrophage: past, present and future. Eur. J. Immunol. 37, S9-S17 (2007).

16. Zanoni, I. \& Granucci, F. Differences in lipopolysaccharide-induced signaling between conventional dendritic cells and macrophages. Immunobiology 215, 709-712 (2010).

17. Van Ginderachter, A. J. et al. Classical and alternative activation of mononuclear phagocytes: picking the best of both worlds for tumor promotion. Immunobiology 211, 487-501 (2006).

18. Swirski, F. K. et al. Identification of splenic reservoir monocytes and their deployment to inflammatory sites. Science 325, 612-616 (2009).

19. Raslova, H. et al. Immunophenotypic study of atypical lymphocytes generated in peripheral blood and spleen of nude mice after MHV-72 infection. Viral Immunol. 13, 313-327 (2000).

20. Guidotti, L. G. et al. Immunosurveillance of the liver by intravascular effector CD8(+) T cells. Cell 161, 486-500 (2015).

21. Hutas, G. et al. CD44-specific antibody treatment and CD44 deficiency exert distinct effects on leukocyte recruitment in experimental arthritis. Blood 112, 4999-5006 (2008).

22. Yang, Y. et al. Effects of anti-CD44 monoclonal antibody IM7 carried with chitosan polylactic acid-coated nano-particles on the treatment of ovarian cancer. Oncol. Lett. 13, 99-104 (2017).

23. Tinianow, J. N. et al. Site-specifically ${ }^{89} \mathrm{Zr}$-labeled monoclonal antibodies for ImmunoPET. Nucl. Med. Biol. 37, 289-297 (2010).

24. Jung, K. et al. ${ }^{89} \mathrm{Zr}$ Labeled anti-PD-L1 antibody PET monitors gemcitabine therapy-induced modulation of tumor PD-L1 expression. J. Nucl. Med. https://doi.org/10.2967/jnumed.120.250720 (2020).

25. Wiranowska, M. et al. Modulation of hyaluronan production by CD44 positive glioma cells. Int. J. Cancer 127, 532-542 (2010).

26. Bollyky, P. L. et al. CD44 costimulation promotes FoxP3+ regulatory T cell persistence and function via production of IL-2, IL-10, and TGF-beta. J. Immunol. 183, 2232-2241 (2009).

27. Graham, V. A., Marzo, A. L. \& Tough, D. F. A role for CD44 in T cell development and function during direct competition between CD44+ and CD44- cells. Eur. J. Immunol. 37, 925-934 (2007).

28. Viana, K. F. et al. Analysis Using Canine Peripheral Blood for Establishing in Vitro Conditions for monocyte differentiation into macrophages for Leishmania Chagasi infection and T-cell subset purification. Vet. Parasitol. 198, 62-71 (2013).

29. Sladek, Z. \& Rysanek, D. CD14 expression, apoptosis and necrosis in resident and inflammatory macrophages from virgin bovine mammary gland. Vet. Med. 59, 467-478 (2014).

30. Nouri-Shirazi, M., Bible, B. F., Zeng, M., Tamjidi, S. \& Bossart, G. D. Phenotyping and comparing the immune cell populations of free-ranging Atlantic Bottlenose dolphins (Tursiops Truncatus) and dolphins under human care. BMC Vet. Res. 13, 78 (2017).

31. Huizer, K., Mustafa, D. A. M., Spelt, J. C., Kros, J. M. \& Sacchetti, A. Improving the characterization of endothelial progenitor cell subsets by an optimized FACS protocol. PLoS ONE 12, e0184895 (2017).

32. Rosmarin, A. G. et al. Differential expression of CD11b/CD18 (Mo1) and myeloperoxidase genes during myeloid differentiation. Blood 73, 131-136 (1989).

33. Schmid, M. C. et al. Integrin CD11b activation drives anti-tumor innate immunity. Nat. Commun. 9, 5379 (2018).

34. Kanevskiy, L. M., Telford, W. G., Sapozhnikov, A. M. \& Kovalenko, E. I. Lipopolysaccharide induces IFN- $\gamma$ production in human NK cells. Front. Immunol. https://doi.org/10.3389/fimmu.2013.00011 (2013).

35. https://www.bio-rad-antibodies.com/static/2017/flow/flow-cytometry-cell-frequency.pdf.

36. https://www.stemcell.com/media/files/wallchart/WA10011-Frequencies_Percentages_Mouse_Immune_Cell_Types.pdf.

37. Hollingsworth, J. W. et al. CD44 regulates macrophage recruitment to the lung in lipopolysaccharide-induced airway disease. Am. J. Respir. Cell Mol. Biol. 37, 248-253 (2007).

38. Gee, K. et al. Differential regulation of CD44 expression by lipopolysaccharide (LPS) and TNF-alpha in human monocytic cells: distinct involvement of c-Jun N-terminal kinase in LPS-induced CD44 expression. J. Immunol. 169, 5660-5672 (2002). 


\section{Author contributions}

J.W.P. co-wrote the original manuscript text. K.-H.J. co-wrote the editing manuscript text. J.H.L., S.H.M. and Y.S.C. prepared figures. K.-H.L. co-wrote the original manuscript text, administrated and supervised the Project.

\section{Funding}

This work was supported by the Basic Science Research Program through the National Research Foundation of Korea (NRF) funded by the Ministry of Science, ICT and Future Planning (2019R1A2C2007455).

\section{Competing interests}

The authors declare no competing interests.

\section{Additional information}

Supplementary Information The online version contains supplementary material available at https://doi. org/10.1038/s41598-021-83496-3.

Correspondence and requests for materials should be addressed to K.-H.L.

Reprints and permissions information is available at www.nature.com/reprints.

Publisher's note Springer Nature remains neutral with regard to jurisdictional claims in published maps and institutional affiliations.

(c) (i) Open Access This article is licensed under a Creative Commons Attribution 4.0 International License, which permits use, sharing, adaptation, distribution and reproduction in any medium or format, as long as you give appropriate credit to the original author(s) and the source, provide a link to the Creative Commons licence, and indicate if changes were made. The images or other third party material in this article are included in the article's Creative Commons licence, unless indicated otherwise in a credit line to the material. If material is not included in the article's Creative Commons licence and your intended use is not permitted by statutory regulation or exceeds the permitted use, you will need to obtain permission directly from the copyright holder. To view a copy of this licence, visit http://creativecommons.org/licenses/by/4.0/.

(C) The Author(s) 2021 